\title{
English Language Dominance and the Fate of Indigenous Languages in Nigeria
}

\author{
Ife Ajepe \\ English Language Unit \\ Department of General Studies \\ Afe Babalola University, Ado-Ekiti \\ Adeyemi J. Ademowo, PhD \\ Cultural Studies Unit \\ Department of General Studies \\ Afe Babalola University, Ado-Ekiti
}

\begin{abstract}
The blind glorification of English language by the elites as well as the defective National Policy on Language has conspired to undermine the local languages and rob them of their importance in national development drive. This paper examines the reason(s) for the continued dominance of English language and its widely accepted usage in all spheres of life, including the social media, in Nigeria. It then evaluates the contributions and the levels of involvements of key stakeholders namely the government, the media, the parents and the youths in the marginalisation of indigenous languages.

The paper suggests that to break the tenacious grip on the colonial master's language which has made it difficult for the vast majority of the Nigerian population to participate in the overall national development, the stakeholders, most especially the government and the media, need to review their attitude towards the indigenous languages.
\end{abstract}

Keywords: Indigenous language, dominance, English language, marginalisation, fate, development.

\section{INTRODUCTION: INDIGENOUS LANGUAGES AND THE EVOLUTION OF NIGERIA}

The multilingual nature of Nigeria has become one of her greatest challenges in recent time. Inconsistent language policy, successive government's inability to pick any of the indigenous languages as a national language, non-codification of many minority languages, inadequate definition of roles for indigenous languages in governance, among others, are some of the major harbinger of this crisis. Although Nigeria has between 250 and 400 indigenous languages (Ogunwale 2013) none of the languages has been considered worthy of adoption as national language. Attempt was made to popularise an artificial language, akin to Swahili of the East Africans, in the 1990s, but that was also unsuccessful as it contains mostly bits of words and vocabularies found only in the three major languages, namely WA (Yoruba); ZO (Hausa) and BIA (Igbo), neglecting the other languages. English Language has since continued to gain so much prominence in the country that its dominance has stifled the growth (and even led to the extinction of some) of the 529 indigenous languages in Nigeria. The dominance, as could be decipher, is not inflicted, but by a natural course of indispensability of the language as its use cuts across different spheres of the nation. However, when one considers the fact that the linguistic situation in Nigeria before colonisation was that in which indigenous languages thrived and promoted cultural values of the people, then it will be expedient to unravel why the indigenous languages suddenly take the back seat.

In the course of colonisation, Nigerian indigenous languages had contact with the language of the colonialists; the latter was more favoured than the former. English language then became the language of colonial administration. At independence the language was bequeathed to Nigeria as a nation, especially because it was the only language that was used for administration, missionary work and later education. Even after attaining independence, Nigeria has not been able to have language policies that could create functions for the indigenous languages. The existing policy which is an aspect of the Education Policy of 1977, has only feebly assigned roles that have been difficult to execute so effectively. The status of these three languages as major languages is captured in the 
National Policy of Education formulated in1977 (and which has subsequently been revised in 1981, 1989, 1998 and 2004). The Nigerian Language Policy is a document of the Federal Government of Nigeria, which has statutory guidelines regarding the official use of different languages in the country. Although the policy documents and stresses the importance of language to national development, as a means of promoting social interaction and national cohesion, as well as preserving the nation's rich cultural heritage, but its implementation has not been diligently executed.

According to the policy, there are three categories of the functionality of Nigerian languages (Adekunle 1976):

Class A: In this category, the Languages are classified by the government as the major indigenous languages; and they are spoken by at least six million native speakers and used widely outside their state of origin by Nigerians with different mother tongues, Examples of this are Hausa, Igbo and Yoruba

Class B: These are officially recognized languages in Nigeria and used at the national level as and federal level but do not enjoy much usage outside the state of their origin. Under this category are; Kanuri, Fulani, Edo, Efik,Tiv, and Ijo, etc.

Class C: These are minor languages with no official recognition at the state level.

Unfortunately, these NPE action-plans exist only on papers and in briefs, because the challenges that will be prevent their pragmatic execution were not addressed. Another factor is the linguistic diversity of the Nigerian constituting nations/peoples. These have hindered the development of Nigerian indigenous languages to the advantage of the growth of English language which has gained more prestige and status in Nigeria. Multilingualism that should ordinarily protect the indigenous languages and ensure diversity through the various cultures has become a serious challenge affecting all facets of life. Today, only three languages out of the 529 languages are recognised as major languages namely, Hausa, Igbo and Yoruba. The others are regarded as minor languages. The obvious reason for these cautious threading is the fact that adopting a language in a multilingual nation is a very sensitive process. When a language is given more roles or prominence, others begin to feel envious just as we have in Nigeria thus making it impossible, so far, to pick an indigenous language as a lingua franca.

Even the so called major languages have not significantly thrived in education beyond their geographical boundaries because of the obvious lack of teachers to teach them in schools (Udosen 2013). The acclaimed minority languages have not made any appreciable impact even within their domains because of the speaker's native attitude to their language among other things (Udosen 2002). All these prepared the ground for an English language to thrive and take the number one position among the 400 Nigerian Languages (Udosen 2013). Hence, the cultural identity which language bequeaths to man has resulted in increasing conflicts especially in multicultural societies like Nigeria.

\section{English Language Dominance in a Multilingual Nigeria}

English language has assumed a global status as a result of its widespread usage by many countries. While some countries use it as a first language, others use it as a second language or as a foreign language. Many of the countries who speak English language were either colonised directly by the British or their proxy, which then ensured the continued usage of English language as a medium of teaching in schools. The reason for English language widely accepted usage as an international language was highlighted by Strevens (1987). According to Strevens (1987:37), 'English was the language used for exploration, trade, conquest and domination from the $16^{\text {th }}$ Century'. The role and functions of the English language, however, changed in 1914 from being an instrument of subservience to other, quite different ends, such as "window on the world of science and technology" or as the only language not rejected by one section of population or another. Since then, a number of activities, movements, and subject were carried out predominantly across the world. This is because the English language practically gained strong grounds in various spheres. Strevens recorded that there was an international agreement to adopt English for air traffic control; and its use in the numerous bodies providing international aid and administration. As the telecommunications revolution developed, English became dominant in the international media, radio and television, magazines and newspapers. Verghese (2007: 100) points out that in the world today, the English language is dominating the space in every country. This is not as a result of self imposition but by virtue of its obvious roles. It is no surprise then, that Nigeria which was a colony of the British 
adopted the English language as the National language especially in the absence of any well developed indigenous language to play the various roles played by the English language in Nigeria.

The absence of a Lingua Franca, and the lack of mutual intelligibility of most of the indigenous languages, has given room for the English language to become nurtured, robust and hegemonic. English is therefore a second language which is learned and used in every sector of Nigeria. Indeed, English language has been institutionalised in Nigeria as the language of integration and unity. To scholars like Adedimeji (2003), English Language has emerged as that privileged language without which the unity of Nigeria as a nation is mostly improbable, if not out rightly impossible. English is the only language either in its Received Pronunciation form (RP) or its Nigerian variety or its pidgin version that is mutually understood by an average Nigerian when two or more people of different ethnic groups want to communicate. Afolayan cited by Jowitt (1991: 123) confirms thus:

It is unrealistic for anybody in Nigeria today to think that national unity can be forged in the country without recourse to the utilisation of the English language; It has been the language of the creation of the political entity itself, and also the language of its political-economic unification and administration.

In the words of Schwarz, cited in Bamgbose (1991:39), differences between indigenous languages keep the people apart, perpetuate ethnic hostilities, weaken national loyalties and increase the danger of separatist sentiment. This lends credence to the fact that English is the only language that is not viewed with suspicion by other ethnic groups and which is acceptable more or less as a lingua franca. To Schwarz, therefore, English is the language of integration in Nigeria. Adegbija (1994: 150) is also of the opinion that deep-rooted mutual suspicions which result in prejudice, stereotypes and subtle linguistic hostility exist among various linguistic groups in Nigeria. Adedimeji (2003) therefore concludes that with English as the common tongue to all the ethnic groups, the collective sentiment of belonging together despite the individual or ethnic differences is forged.

As it were today in Nigeria, language of education, the language of the legal system, the language of telecommunication and technology. It is the language of government, commerce and industry and the language of print and electronic media. It is also the language used in religious settings like churches, where sermons are delivered in English language and later interpreted into the local languages. Bamgbose (1971: 35) further affirms the place of English holding that "Of the entire heritage left behind by the British, at the end of the colonial administration, probably, none is more important than the English language". Although the 1977 Language Policy gives room for the use of indigenous languages, but in practice, the English language is the language of governance in Nigeria. Babajide (2001: 4) underscore the vital place of English further:

Given the many important roles that English language performs, it becomes expedient for any Nigerian that wants to be relevant to his social, economic and political environment to learn and acquire some appreciable knowledge of English. This explains why both the literate and non-literate have a great respect for anyone who has an admirable proficiency in English. In fact, educated Nigerians who are deficient in their mastery of English and some of the uneducated lot make frantic efforts through private tuition to learn it.

The English language is also the language of education in Nigeria. It is the language used for instructions in most schools from kindergarten to university. This is contrary to the National Policy on Education (NPE) of 1977 revised in 1981 states in Section 2 paragraph 7 which states that "the medium of instruction in pre-primary schools shall be the language of immediate community. English may be used as a medium of instruction, but the language of the immediate community should be taught in the spoken form". Section 3 Paragraph 15(4) of the NPE further states that "government will see to it that the medium of instruction in the primary schools is initially the mother tongue or the language of immediate community and at a later stage English" unfortunately, most schools at the early primary school use the English language as a medium of instruction. In fact, many of such schools often prefer not to offer any indigenous languages in their curriculum. To many of such schools, using English language often gives the pupils better foundation in English language influent distraction (Ademowo 2016).

The attitude of parents to the use of mother tongue or the language of immediate community has also not been encouraging; most parents prefer that the child starts with the English language, so the schools are made to do so, especially as most children are spoken to in the English language from 
birth. The English language therefore becomes the first language of most children. Similarly, it is the language that every student is expected to pass at every level of the educational ladder to confirm their brilliancy.

Early newspapers in Nigeria were launched and widely read during the colonial era when English Language was the language of administration and print. This has therefore been continued as the language of wider communication. Few Newspapers and magazines were written in indigenous languages and this has been the trend since then, as most indigenous languages are not codified to be useful as a language of wider communication. English is therefore the language of the media. Almost all the programmes aired in the television and radio stations are done in English Language. The English language has thus dominated every other language in our media houses. The Nigerian Tribune, This Day, The Guardian, Daily Trust, City People among others are few examples in the print media. The Nigeria Television Authority (NTA) broadcasts its news in the English language. It is only in the states, that the most prominent local languages are used to broadcast the major news.

The major language used in telecommunication industry is English language with occasional interpretations in the three major languages. Sports commentaries during tournaments are usually done in the English language. Only recently a major football tournament had done its commentaries in Pidgin language on National Television. The fall-out of this was criticisms from the Elite Nigerians who speak Pidgin under normal circumstances. Similarly, English is the language of advertisement in print and electronic media.

The first democratic elections conducted in Nigeria were by the British. The politicians therefore had to and continue to play Politics on the platform of the English language. It is the language of campaign, it is the language in which manifestos are printed and read, though sometimes translated later to major indigenous languages. It is the language used for handbills and posters. Politician who wants to be elected for a position are often also judged by how proficient and articulate he/she is in the use of the English language. An illiterate appreciates having a leader who speaks the language well .A leader who cannot express himself fluently in English language is considered a disgrace in the committee of other leaders; hence, voters put that into consideration when electing a candidate, to choose someone they can be proud of and who can be respected in the committee of other leaders. No indigenous language has been so recognised and developed as to be able to challenge the status quo since independence.

The fact that only three major languages are recognised in Nigeria amongst several other languages has necessitated that the Constitution be written in the English language; so also are official gazettes and other vital documents. It is the language for communication at all the strata of government from the federal to the local government. All government activities and transactions are equally carried out in the English language.

Prior to the 1980's, orthodox churches carried out church activities in the language of the immediate environment. However, with the advent of Pentecostalism, whereby there is a Youth movement and evangelism of young people, English became the language of sermons and all church activities, as it is the language that would attract the young ones who are mainly students. When the Pentecostal churches realised they were losing many of their young members, they began to also use English language substantially in their activities with interpretation in the local language of the immediate environment for those who may not understand the English language.

These are major, but not all areas in which the English language is playing very significant roles in Nigeria at the detriment of the growth of indigenous languages.

\section{The Fate of Indigenous Languages in Contemporary Nigeria: EXTinction THREATS}

The dominance of the English language in Nigeria has naturally relegated the use of the indigenous languages. This has far reaching effects, culturally and linguistically on the identity of a nation. For example, the use of indigenous languages among children is getting reduced. The implication of this is that, many languages or dialects now face the threat of language extinction, language shift or ultimately language death. A language if not spoken eventually dies. Language and culture cannot be 
separated; therefore the lack of use of indigenous languages by the younger generation has led to the gradual erosion of our cultures. The result of this is that the younger generation are beginning to lose the core values and virtues in their cultures. The dress culture of the younger generation is also taking after the dress culture of the people whose language they speak. The younger generation is reflecting the culture of the language they speak more by gradually and modifying their names to be pronounceable in English.

Oke (2013:90) in a study came up with the following Yoruba names on the social media platform:

\begin{tabular}{|c|c|}
\hline Names in Original Yoruba Versions & Anglicized Version of the Names \\
\hline Ayomide & Haryurmideh \\
\hline Oyindamola & Hoyindarmorlah \\
\hline Adedoyin & Ardeydhoyin \\
\hline Abisola & Harbeesorlah \\
\hline Femi & Phemmy \\
\hline
\end{tabular}

To Oke (2013), this younger generation of Yoruba speakers assumes that non-Yoruba speakers are likely to have problems with most of these names if written in their original Yoruba patterns. Thus, they result to Anglicising indigenous Yoruba personal names without considering the effects on the indigenous languages. Oluga \& Babalola (2012:619), opine that there are severe implications for the decline in the use of indigenous languages. These implications include but are not limited to linguistic and cultural disadvantages. According to Oluga\&Babalola (2012):

The dominant use of English in Nigeria has negatively affected the quality of the indigenous languages used by many especially the elite. They can hardly speak pure or undiluted Yoruba, Igbo or Hausa without code mixing with lexemes or phrases of English or code switching from Yoruba, Igbo or Hausa to English intermittently.

The effectiveness of the mother-tongue for educational purposes, was proved by the research project in Ife, where Fafunwa (1984) experimented on a six year primary education project and it was found out that pupils who were taught with Yoruba at the primary school level performed better than their counterparts who were taught with purely English language. In his words, "the child learns better in his mother tongue and his mother tongue is as natural to him as his mother's milk" (Fafunwa 1983: 395). If the English language continues to play the role of national language, the role of lingua franca, the role of unity language in a multilingual and heterogeneous country like Nigeria, and remains the language of education, media, legislation and permeates through the entire fabric of the Nigerian society, then indeed the indigenous languages are not merely under threat but dying gradually.

A language that has assumed and acquired such a status will naturally be of unique interest to diverse persons in Nigeria; more so when adequate proficiency in such language is attached to career and social growth. And when proficiency in the same language opens certain doors to those who have it, and commands respect everywhere it is displayed. Attempts to promote the use of indigenous languages have also been roundly frustrated. While some parents would love their children to be able to speak their indigenous languages, they are equally more concerned with the education and future of these children which is tied to high proficiency in the English language. If at every point in life, the criterion for measuring, success and social status is the English language, there is a mix- bag of questions as to where to lay the emphasis. Many parents have therefore chosen to start promoting English language proficiency at very early stage of their childhood since it is the language with which they will be expected to function for the rest of their schooling and working lives. Educated parents who know that a child is capable of acquiring many languages before age 12, will rather prefer the child learns first, the language that appears most functional in the society which is English and later naturally acquire the mother tongue which serves lesser roles as it were. Gradually L1 (First language acquired) is therefore being replaced with L2 (Second language learned). For many parents, the submission of UNESCO that the mother tongue enhances the learning of the second language"' does not matter to them because they are eager to see their children get proficient, think and reason in the language they will need to use for the rest of their lives if they want to remain at the upper echelon of 
the social strata. The question then is where is the meeting point for the actualisation of the two objectives of being globally relevant and promoting the use of indigenous languages in Nigeria?

\section{Between Global Relevance and SAVING Dying LANGUAgeS}

To start with, the Nigerian government needs to develop a language policy that vigorously and effectively promotes Nigerian indigenous languages in all schools, and making the learning of at least one indigenous language compulsory in all schools rather than optional, as it is currently. Generally speaking, a lot of effort is being made to promote the use of indigenous languages already. This cuts across music, movies, advertising, internet and others. In the music industry, many of our hip hop artists now sing a mixture of Igbo/ English, Yoruba/English, Efik/English songs. Hausa/English is also not left out. This local flavour makes the contemporary music appeal to both the young and the old in Nigeria.

In the movie industry, indigenous languages are being promoted in the three major languages. The MNET and other satellite television providers now have designated channels for Igbo, Yoruba and Hausa African movies. The viewership of these channels cut across all ages. The young ones who do not speak these languages fluently are not left out in patronage when it comes to watching indigenous movies. It is important that other Languages are also promoted in this regard. Film producers can go to the grassroots to train local actors in the other minority languages pending when some of these languages will be taught in the tertiary institutions.

Telecommunication service providers have come to realise that to get to the grassroots, they must communicate with them in the language they understand. Many of the advertisements in print and electronic media therefore have their equivalents at least in the three major languages. Few other multinational companies do this, but it can still be emulated by all companies who wish to advertise their products to the public. This can be a matter of policy by the advertising regulatory board. For example, it can be stipulated that any bill board to be placed in any community must be translated in the language of the immediate community as a matter of policy.

The internet will be a veritable source of promoting indigenous languages, if adequate efforts can be put in. The world wide web, is accessed all over the world and Nigeria's participation cannot be underrated due to its population. While efforts are already being put in place on minimal levels such as the ability to Google in the three major languages, and few indigenous platforms like 'Proudly Yoruba and Ábiyamo exist. However much more can still be done in Nigeria on social medias like WhatsApp, Face - book etc to promote not just the three major languages, but many of the coded indigenous languages. In line with this, young Nigerians should be encouraged to present their names on Face - book exactly the way it is pronounced and spelt in their indigenous languages Ayomide should be spelt as such and not Aryourmidey They should promote their own language by making foreigners learn how to pronounce the names as they are, rather than trying to please their foreign friends whom some of them have never even met not to talk of having the ability to add serious values to their lives.

Parents should therefore be enlightened on the advantages of speaking the indigenous language/ mother tongue to their children as their first language. Similarly, schools should be advised to stop punishing students for speaking 'vernacular' in school. Policy implementers should ensure the use of mother tongue or language of immediate environment is used to teach pupils at junior primary school level and junior secondary school.

As highlighted earlier in the study of Oke (2012) and Bamgbade (2012) several Researches have shown that the problem of using and promoting indigenous languages is more prominent in the Southern and Western Nigeria. Perhaps other tribes should begin to take a cue from the Northern ethnic groups in Nigeria. A typical Hausa family speaks Hausa language or Fulani or Kanuri to their children from birth, as the case maybe. A Hausa man does not care whose ox is gored or who is not comfortable with his use of his language either at home or in the public space or in government instititutions. The Northern tribe are so passionate about their language, that a foreigner who can speak their language at whatever level of proficiency is immediately regarded as a friend.

History recalls that during the colonial rule, part of the preconditions for allowing the colonialist set up schools in the Northern region, was that their children will be allowed to be taught also in their indigenous language. While this led to the lope sidedness of growth in education between the southern 
and the Northern Nigeria, an inherent advantage is that the Northern child is not separated from his culture and language, and is insulated greatly from foreign influence in his cultural values.

In view of the above, the government should begin to look into the possibility of having regional Lingua Francas. While Hausa is adopted in the north and assigned functional roles, Yoruba can be adopted in the South West with its roles in education, judiciary, media etc. The Igbo language can be adopted for the southeastern part of the country. Ethnic rivalry induced by the recognition of one language over the other will be reduced greatly. The English language should continue to function as the national language but not the Lingua Franca. It should remain a language to be taught in the schools and be used to teach students at senior secondary levels. It should remain a language for relating with the outside world, but given less importance in the day to day activity of the citizens.

Indigenous languages should also be taught at general studies level in higher institutions. The teaching should, however, not just be theoretical but practical in all ramifications, which means that examination of these indigenous languages should include test in both oral and writing competence.

\section{Conclusion}

This study highlights reasons for the dominance of English language in Nigeria and why the domination has grew and become stronger overtime, and why some opined that the dominance cannot be easily wished away. If one considers the likely effects the continued domination will have on the indigenous languages and cultural identity of the people in view of the present attitude towards the indigenous languages on the parts of the youths, the parents and the government officials, then one is bound to be worried about the future of the Nigerian cultures. However, if strategies and actions suggested in the work are put place, it is believed that there would be a formidable meeting point between the achievement of the objective of being globally relevant and effective cum efficient promotion of the indigenous languages; but if we continue with the status -quo without conscious effort being put in place then fulfilling both objectives may continue to be a mirage rather than reality in Nigeria. In other words, a proper implementation of a multilingual language policy is vital and expedient.

\section{REFERENCES}

[1] Adedimeji, M.A. (2003). 'The unifying role of English in multilingual nation: The case study of Nigeria'. Retrived March 16, 2015. http://unilorin.edu.ng/publications.

[2] Adegbija, E. (2004). Multilingualism: A Nigerian case study. African World Press.

[3] Adegbija, E. (1994). The context of language planning in Africa: an illustration with Nigeria”. In Putz, M (ed) Language contact and language conflict. Amsterdam/Philadelphia: John Benjamins.

[4] Ademowo A.J. (2016) 'Indigenous Languages and the Development Question in Africa' International Journal of History and Cultural Studies (IJHCS), Vol.2, Issue 1

[5] Ademowo A.J. (2012) 'Indigenous Languages and Techno-Scientific Development in Africa'. Volume 23, No. 2. Lumina. p.1-18

[6] Babajide, A.O. (2001). Language attitude patterns of Nigerians. In H.Igboanusi(ed) Language Attitude and language Conflict in West Africa.

[7] Bamgbade, O.E. (2012). Some issues of English language in Nigeria. University of Ibadan Department of Linguistics Seminar.

[8] Bamgbose, A. (1991). Language and the nation: the language question in Sub-Saharan Africa. Edinburgh: Edinburgh University Press.

[9] Bambgose, A. Et. Al. (1995). New Englishes: A West-African perspective. Ibadan, Nigeria.

[10] Ekpe, ... (2004). Glocalisation of English lexis in Nigeria. Calabar journal of liberal studies (CAJOLIS) Vol ix, No 1. Pp 29- 40.

[11] Isayev, M.I. (1977). National language in the USSR: problems and solutions. Moscow: Progress Publications.

[12] Jowitt, D. (1991). Nigeria english usage: an introduction. Lagos: Longman.

[13] Fafunwa, B. (1983). Yoruba in education. In Afolayan, A. (ed.) Yoruba language and literature. Ibadan: UIP/UPL. 
[14] Oderinde, B.B. (1996). Psychological implications of Mother - Tongue medium in Education. In Education in the Service of Humanity. Ibadan: ERSG. University of Ibadan.

[15] Ogunwale, J.A. (2013). Harnessing multilingualism in Nigeria for development; the challenges and strategies. International journal of English \& literature. Vol 4(8) Pp 368.

[16] Oke, R. (2013). Sociolinguistic dimension to globalisation: gradual shift in Yoruba personal names among Youths in Southwestern Nigeria. The African symposium: an online journal of the african educational research network. Volume 13,no 1. Pp. 93.

[17] Olabode, E.A (2010). Indigenous languages in Africa and their forgotten values. A paper presented at the $3^{\text {rd }}$ International Conference of Centre for Issues in African Development. Kumasi Ghana: Tresureland Conference Centre.

[18] Oluga, S.O \& Babalola, H.A. (2012). Official use of English and the result of marginalisation of indigenous African languages: the cases of the three major Nigerian languages. European journal of social sciences. Vol 32.No 4.Pp619-631)

[19] Strevens, P. (1987). English as an international language. In ''English Teaching Forum'” Oxford Pergamon.

[20] Verghese, P. (2007). Teaching English as a second language. New Delhi: Sterling Publishers private limited.

[21] Yen, C. (2008) Globalisation and English language teaching and learning: challenges and trends. Retrieved March 10, 2015 from: http://afl.usc.edu.tw/Conference\%20.

\section{AUTHORS' BIOGRAPHY}

Ife Ajepe, teaches in the General Studies and English \& Literary Studies departments of Afe Babalola University, Ado-Ekiti. She is a doctoral student in the department of English Language, University of Ilorin, Nigeria. Her areas of interest include Sociolinguistics, Pragmatics and Applied Linguistics.

Adeyemi J. Ademowo (PhD) is a Senior Lecturer in Cultural Studies (Indigenous Knowledge), General Studies Department, Afe Babalola University, Ado-Ekiti. His areas of interest include Indigenous Knowledge, Conflict and Culture Studies, African Philosophy, Change Management, Folklore Studies and Anthropology of Space. 